\title{
Brief communication: maxillary lateral incisor morphology and uncommon trait expression: a case study from prehistoric Paa-ko, New Mexico
}

\author{
Erin C. Blankenship-Sefczek \\ The Ohio State University, Columbus, OH 43210
}

\begin{abstract}
Key words: Dental morphology, Upper Central Incisors, Discrete Dental Trait, Prehistory, Iberian Peninsula.
\end{abstract}

ABSTRACT Prehistoric American Southwest exhibits a high frequency of dental morphological variability. This high variability may be the result of gene flow and subsequent genetic drift occurring in early periods (pre CE 900), though few studies report on dental variability in later periods. Morphological traits of the maxillary lateral incisors were analyzed from the Pueblo IV site of Paa-ko,

Dental morphological traits, such as shoveling, tuberculum dentale, and interruption groove, reflect population affinity and movement (Scott and Turner, 1997). Within the New World, the greatest dental morphological variability is found in the prehistoric American Southwest (Scott et al., 1983; Bailey-Schmidt, 1995; Scott and Turner, 1997; McClelland, 2003; Kuba, 2006).This high variability may be a result of migration and genetic drift, as introduction of new genes and subsequent population isolation changes the expression of dental traits (LeBlanc et al., 2008).Mitochondrial DNA evidence from the prehistoric Southwest region suggests there was migration followed by population isolation in several areas, including the New Mexico Pueblo region (Malhi et al., 2003). Archaeological evidence indicates migration into the Southwest from surrounding areas prior to the Pueblo IV period (CE 900-1500; Wilcox and Haas, 1994; LeBlanc, 1999; Malhi et al., 2003; LeBlanc et al., 2008) was likely a response to resource unpredictability caused by warm droughts and high seasonal resource stress (Dean, 1996; Benson et al., 2007). Unfortunately, few bioarchaeological studies dealing with dental morphology in the later Pueblo IV period have been produced, limiting our ability to address this pre-contact period of population movement. This study interprets dental morphology of one tooth, the maxillary lateral incisor, from the site of Paa-ko, New Mexico in order to add to our understanding of Southwest
New Mexico (CE 1300-1425) yielding high frequencies of four traits (shovel, double shovel, tuberculum dentale, interruption groove) and uncommon variants (barrel-shovel, triform, pegshaped). Lateral incisor morphology is underrepresented in the literature but could be useful in determining population migration and affinity.

dental morphological variability.

Expressions of discrete dental traits are used to determine biological distance, population movement, and evolutionary trends (Turner et al., 1991; Scott and Turner, 1997; Irish and GuatelliSteinberg, 2003). Maxillary lateral incisors, having the highest amount of variation in trait expression of all tooth types, is a key tooth for understanding genetic relationships and population comparisons (Turner et al., 1991; Bailey-Schmidt, 1995; Scott and Turner, 1997). Scott and Turner (1997:32) describe categories of discrete trait variation in maxillary lateral incisors, including barrel-shovel, triform, and peg-shaped or conical incisors, which deviate from the more prevalent morphological forms of shovel and tuberculum dentale.

Studies on dental morphology throughout the prehistoric American Southwest reveal higher variability of maxillary lateral incisor trait expression than any other location worldwide, particularly for shovel, barrel shovel, and full expression of tuberculum dentale and its variants (Sofaer et al. 1972; LeBot and Salmon 1977; Turner and Swindler 1978; Kieser and Preston 1981; Bailey-

Correspondence to: Erin C. Blankenship-Sefczek

The Ohio State University

Department of Anthropology

4034 Smith Laboratory

174 W. 18th Ave.

Columbus, $\mathrm{OH} 43210$

(916) 752-2436

blankenship-sefczek.1@buckeyemail.osu.edu 
Schmidt, 1995; Scott and Turner 1997; Burnett and Weets 2001; McClelland 2003; Bollini et al., 2008; LeBlanc et al., 2008). This study analyzes the frequency of maxillary lateral incisor traits from the prehistoric site of Paa-ko, New Mexico (CE 13001425), adding to the literature on Pueblo IV Southwest dental morphology.

\section{MATERIALS AND METHODS}

Skeletal remains analyzed for this study were recovered from Paa-ko, New Mexico between 1935 and 1937 as a joint venture of the Museum of New Mexico, the School of American Research, and the University of New Mexico, with funds allotted by the Works Progress Administration (Lambert, 1954).

Paa-ko is located between Albuquerque and Santa Fe, New Mexico (Lambert, 1954). Occupied from CE 1300-1425, Paa-ko was established through population migration during the Pueblo IV period (Lambert 1954). This study uses a population count of 178 individuals, the majority of which are infants and children (9 years of age and younger). Taphonomic processes affecting the recovered dentition include severe postmortem damage and postmortem loss, both of which impacted observation and recording. For this study, only individuals with intact, fully erupted anterior maxillary dentition were used. Dental morphology was observed and recorded for 53 maxillary lateral incisors associated with 34 individuals; nine subadults (10-17 years), and 25 adults (18 + years). Males and females were not considered separately because of low correlation between sex bias and trait expression (Scott and Turner 1997; Kuba 2006).

Dental morphology of 37 discrete and continuous dental traits were examined and scored following the extensive sequencing of Turner et al's (1991) ASUDAS to ensure accurate recognition. For this study variations of shovel, double shovel, interruption grove, and tuberculum dentale were the focus. In cases where dental attrition or taphonomic processes inhibited scoring of morphological traits, traits were recorded as missing data.

\section{RESULTS}

Fifty-three maxillary incisors from 34 individuals were examined. Table 1 shows trait frequencies.
TABLE 1. Frequency of Lateral Incisor Trait

\begin{tabular}{llc}
\hline Traits & \multicolumn{2}{c}{$\begin{array}{c}\text { \# of Individuals } \\
\text { Scored and Percent } \\
\text { Expressed }\end{array}$} \\
\hline Shovel & $\mathrm{n}$ & $\%$ \\
Full Shovel & 26 & 0.790 \\
Marked & 8 & 0.235 \\
Barrel & 5 & 0.147 \\
Double Shovel & 1 & 0.290 \\
Interruption Groove & 12 & 0.350 \\
Tuberculum dentale & 22 & 0.610 \\
$\quad$ Well-developed & 13 & 0.647 \\
Triform & 1 & 0.382 \\
Peg-shaped & 4 & 0.029 \\
\hline
\end{tabular}

The most frequently expressed trait was shoveling, occurring in 26 individuals $(79 \%, n=43$ teeth). Of these individuals, 13 (38.2\%, $\mathrm{n}=13$ teeth) exhibit either shovel, or marked shovel (Turner et al. 1991). Barrel-shaped incisor was exhibited in one individual (2.9\%, $\mathrm{n}=2$ teeth). Double shoveling was exhibited in 12 individuals ( $35 \%, \mathrm{n}=17$ teeth). Interruption groove was expressed in 21 individuals $(61 \%, \mathrm{n}=32$ teeth). Tuberculum dentale was present in 22 individuals $(64.7 \%, \mathrm{n}=35$ teeth). Thirteen of the individuals (55.8\%, n=19 teeth) with a tuberculum dentale expressed either a weak cuspule with a free apex or a strong cusp with free apex, which are the highest ASUDAS grades (Turner et al 1991:16). One individual $(2.9 \%, n=1$ tooth) expressed a triform, bifurcated lateral incisor. This tooth exhibited a developed transverse ridge on the incisal surface originating from the tuberculum dentale dividing two fossae (Lee et al. 1988; Bailey-Schmidt 1995). Mesiodistal and labiolingual dimensions of this tooth were greatly expanded as a result of this morphological arrangement. Four individuals $(11.7 \%, n=4$ teeth) expressed a peg-shaped, or conical, lateral incisor. Eight individuals $(23.5 \%, \mathrm{n}=11$ teeth) expressed some degree of all observed traits (shovel, double shovel, interruption groove, tuberculum dentale). Six individuals $(17.6 \%, \mathrm{n}=7$ teeth) exhibit maxillary lateral incisor variants which are considered rare in expression (barrel-shovel, peg-incisor, triform; Scott and Turner, 1997). 


\section{DISCUSSION}

Paa-ko is a quintessential example of prehistoric Southwest dental morphological variation. There is a high prevalence of all four maxillary lateral incisor traits analyzed (shovel, double shovel, tuberculum dentale, and interruption groove) and most correspond with previously reported Native American samples (Sofaer et al., 1972; Scott et al., 1983; Bailey-Schmidt, 1995; Scott and Turner, 1997; McClelland, 2003). Seventeen percent of the Paa-ko sample exhibits uncommon lateral incisor trait variants, barrel-shovel (Figure 1), triform (Figure 2), and peg-shape (Figure 3), a higher frequency than other reported prehistoric Southwest populations (Sofaer et al., 1972; Burnett and Weets, 2001; McClelland, 2003).

An outline of specific migration patterns is beyond the scope of this paper because its focus

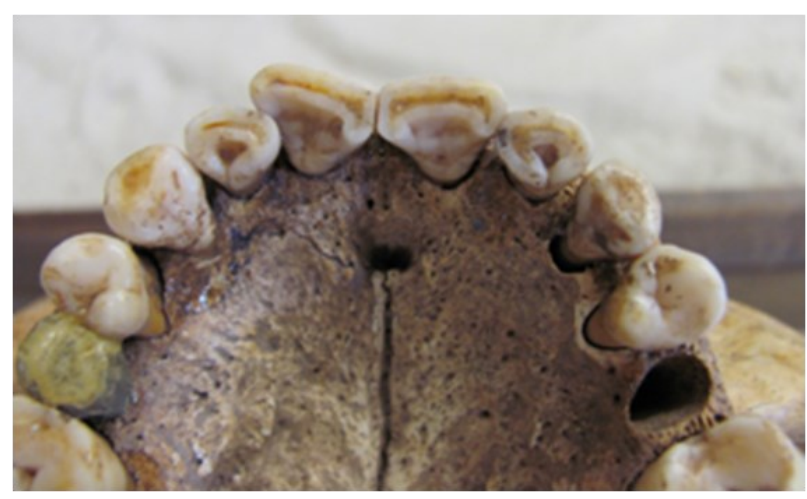

Fig. 1. Barrel-shovel lateral incisors observed in burial 1971-82-122.

remains on one population; however, a discussion is necessary to determine the high variability and rare trait expression within the maxillary lateral incisor of Paa-ko. Increased trait prevalence is most likely the result of gene flow into the Southwest followed by period of population isolation (Malhi et al., 2003; LeBlanc et al., 2008). Migration into the region, including into the San Juan Basin (Benson et al., 2007) where Paa-ko is located, occurred prior to the Pueblo IV period. Lambert (1953) argues that Paa-ko was established by communities from the west. High frequencies of morphological variation and prevalence of uncommon traits may be reflective of the broad admixture resulting from eastern migration (Malhi et al., 2003).The Pueblo pattern of large site abandon-

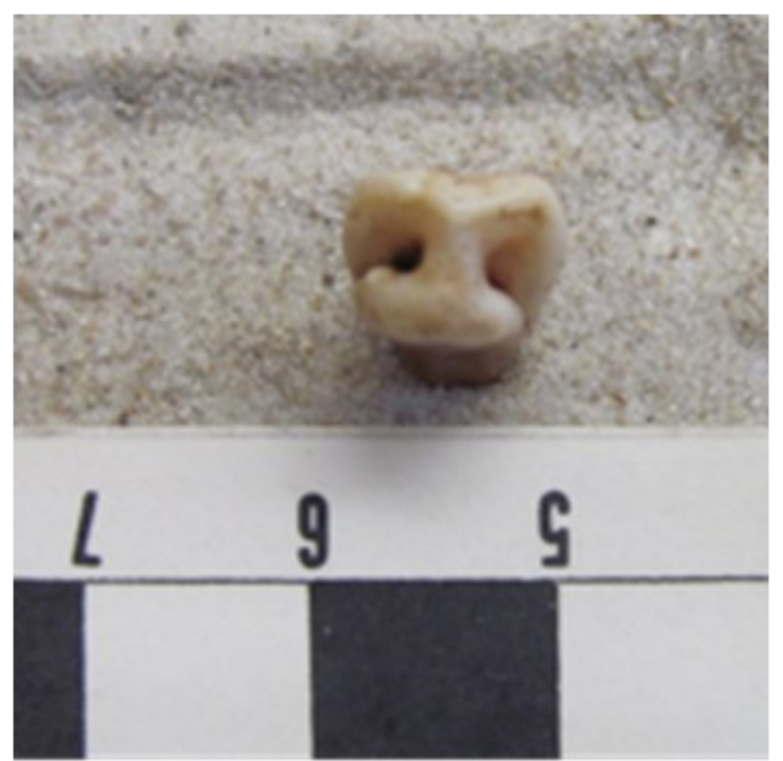

Fig. 2.Triform variant of right lateral incisor observed in burial 1971-82-21.

ment followed by isolated community aggregation (Fagan, 2000) likely resulted in short term genetic drift, and contributed to the higher prevalence of rare dental traits observed within Paa-ko.

Adaptive significance can also influence the expression of certain dental traits, as functional demands impact tooth morphology (Hunter and Jernval, 1995). Shoveling and tuberculum dentale may be adapted to strengthen teeth by adding to structural durability with extra enamel (Dahlberg, 1963; Bailey-Schmidt, 1995).However, this explanation is less likely to be the case because traits

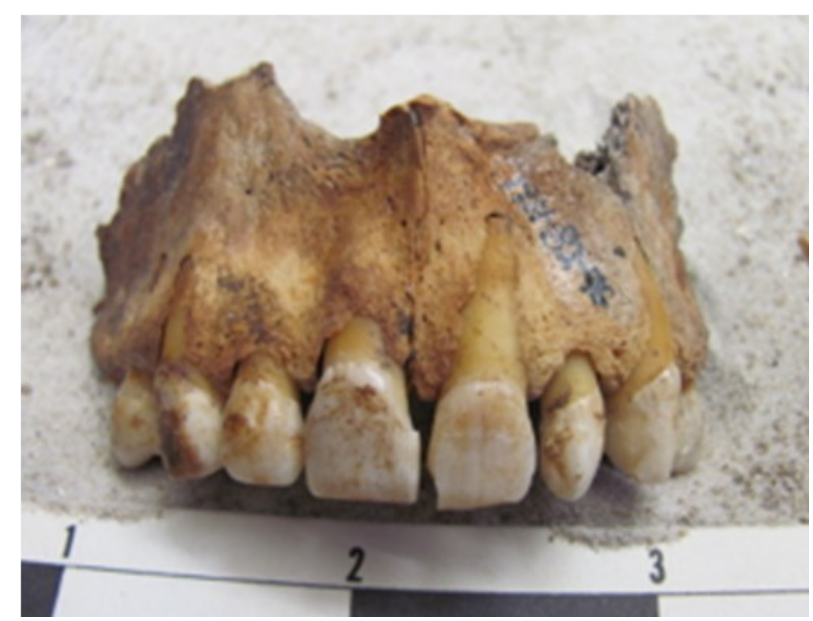

Fig. 3. Peg-incisor observed on left maxillary lateral incisor of burial 1971-82-96. 
associated with advantageous adaptive changes would be seen in high prevalence throughout the region, not localized to Paa-ko. Additionally, anterior teeth are not used in primary mastication.

\section{CONCLUSION}

Prehistoric Native American Southwest exhibits high dental variability in the lateral incisors (Sofaer et al., 1972; Bailey-Schmidt, 1995; Scott and Turner, 1997; McClelland, 2003), especially at Paako, New Mexico (CE 1300-1425). High prevalence of four discreet traits (shovel, double shovel, interruption groove, and tuberculum dentale) and their morphological variants (barrel-shovel, pegincisors, triform) were observed in Paa-ko, New Mexico. The high observed variability is likely the result of gene flow into the region followed by short term population isolation prior to the Pueblo IV period (CE 900-1500). Even though maxillary lateral incisor traits are good indicators of genetic relationships and population movement (Scott and Turner, 1997), they are underrepresented in the literature. This article provides an additional prehistoric Southwest population for future research on regional behaviors, migration, and population affinity.

\section{ACKNOWLEDGEMENTS}

Thanks go to the San Diego Museum of Man for the opportunity to conduct research on this collection. To Tori D. Randall, thank you for your support of this project. Thank you to G. Richard Scott, and Shara Bailey for aiding in the identification of the triform lateral incisor. Special thanks go to Debbie Guatelli-Steinberg for guidance and advice in analysis and writing. The author thanks the editor-in-chief Christopher W. Schmidt and anonymous reviewers for their critical advice on this work.

\section{LITERATURE CITED}

Bailey-Schmidt S. 1995. Population distribution of the tuberculum dentale complex and anoma lies of the maxillary anterior teeth.Masters the sis, Department of Anthropology, Arizona State University.

Benson LV, Berry MS, Jolie EA, Spangler JD, Stahle DW, Hattori E.M., 2007. Possible impacts of early-11th-, middle-12th, and late-13th century droughts on western Native
Americans and the Mississippian Cahokians. Quaternary Science Reviews 26: 336-350.

Bollini GA, Rodriguez-Florez CD, Colantonio, SE. 2008. Dental non-metric traits in a preconquest sample from Tastil region in Argentina South America. Bulletin of the International Association of Paleodontology 2(1): 1925.

Burnett SE, Weets JD. 2001. Maxillary caninefirst premolar transposition in two Native American skeletal samples from New Mexico. Am J Phys Anthropol 16: 45-50.

Dahlberg AA 1963. Dental evolution and cul ture. Human Biology 35: 237-249.

Dean JS. 1996. Demography, environment, and subsistence stress, In: Tainter JA, Tainter BB (Eds), Evolving Complexity and Environmental Risk in the Prehistoric Southwest.

Fagan BM. 2000. Ancient North America: the archaeology of a continent. New York: Thames and Hudson.

Hunter JP, Jernvall J. 1995. The hypocone as a key innovation in mammalian evolution. Pro ceedings of the National Academy of Sciences, USA 92: 10718-10722.

Irish JD, Guatelli-Steinberg D. 2003. Ancient teeth and modern human origins: An ex panded com parison of African Plio-

Pleistocene and recent world dental samples. J Hum Evol 45: 113-144.

Kieser JA, Preston CB. 1981. Dentition of the Lengua Indians of Paraguay. American J Phys Anthropol 55: 485-490.

Kuba CL. 2006. Nonmetric traits and the detec tion of familial groups in archaeological re mains. Dissertation, Department of Anthropol ogy, Arizona State University.

Lambert MF, 1954.Paa-ko, Archaeological chroni cle of an Indian village in north central New Mexico. The School of American Research, Monograph 19, Parts I-V, Santa Fe, NM.

LeBlanc SA. 1999. Prehistoric Warfare in the American Southwest. University of Utah Press, Salt Lake City, Utah.

LeBlanc SA, Turner II CG, Morgan ME. 2008. Genetic relationships based on discrete dental traits: Basketmaker II and Mimbres. Intl J Osteoarchaeol 18: 109-130.

Le Bot P, Salmon D. 1977. Congenital defects of the upper lateral incisors (ULI): Condition and measurements of the other teeth, measurements of the superior arch, head and face. Am J 
Phys Anthropol 46: 231-244.

Malhi RS, Mortensen HM, Eshleman JA, Kemp BM, Lorenz JG, Kaestle FA, Johnson JR, Gorodezky C, Smith DG. 2003. Native American mtDNA prehistory in the American Southwest. Am J Phys Anthropol 120: 108-124.

McClelland JA. 2003. Refining the resolution of biological distance studies based on the analysis of dental morphology: detecting subpopulations at Grasshopper Pueblo. Dissertation, Depart ment of Anthropology, University of Arizona.

Scott GR, Yap Potter RH, Noss JF, Dahlberg AA, Dahlberg T. 1983. The dental morphology of Pima Indians. Am J Phys Anthropol 61: 1331.

Scott GR, Turner II CG, 1997. The anthropology of modern human teeth: Dental morphology and its variation in recent human populations. Cambridge University Press, Cambridge, UK..

Sofaer JA, Niswander JD, MacLean CJ, Work man PL. 1972. Population studies on Southwest Indian Tribes. V. Tooth morphology as an indicator of biological distance. Am J Phys Anthro pol 37: 357-366.

Turner CG II, Nichol, CR, Scott GR. 1991. Scoring procedures for key morphological traits of the permanent dentition: The Arizona State Uni versity Dental Anthropology System, In: Kelly, M.A., Larsen, C.S. (Eds.), Advances in Dental Anthropology. Wiley-Liss, Inc., New York, pp. 13-31.

Turner CG II, Swindler DS. 1978. The dentition of New Britain West Nakanai Melanesians.VIII Peopling of the Pacific. Am J Phys Anthropol 49: 361-372.

Wilcox DR, Haas J. 1994. The scream of the butterfly: Competition and conflict in the prehistoric Southwest, In: Gumerman GJ (Ed.), Themes in Southwest Prehistory. School of American Research Press, Santa Fe, NM, pp. 8108. 